\title{
Strategy as a Culturally Dependent Phenomenon: The Interpretation of Japanese Corporate Strategy THROUgh the ANAlysis of Aikido
}

\author{
Michael J. Cotter \\ Grand Valley State University \\ Grand Rapids, Michigan \\ Morgan P. Miles \\ Georgia Southern University \\ Statesboro, Georgia \\ James A. Henley \\ University of Tennessee at Chattanooga \\ Chattanooga, Tennessee
}

Japanese Maxim: "Alto no saki-Take your opponent's technique and turn it into your own."

"If Japan told Washington it would no longer sell computer chips to the United States, the Pentagon would be totally helpless. Furthermore, the global military balance could be completely upset if Japan decided to sell its computer chips to the Soviet Union instead of the United States" (Ishihara 1989).

The first popular maxim describes many of the corporate strategies and industrial policies implemented by post-war Japan in their intense struggle with the West for economic success and influence. The second statement represents the changing perspective of post war Japan, suggesting as Japan prospers it must exercise more economic, political, and ultimately military power (Ishihara 1989). As Western business leaders utilize combative sports based strategies for marketing purposes, so the Japanese use a martial art orientation in the development of their business strategies and tactics. While a number of similarities exist between traditional U.S. sportive combat skills and traditional Japanese combat techniques, there are significant differences with opposing approaches and strategies. Western firms competing with Japanese keiretsus, coordinated industrial groups composed of manufacturers/trading companies/banks (Johnson 1985), may gain a substantial competitive advantage by understanding the basic principles and tactics that underlie and color much of Japanese corporate strategy.

\section{Purpose}

The purpose of this manuscript is to offer an interpretation of examples of Japanese strategic behavior through the cultural phenomenon of a Japanese martial art, aikido. Two aikido techniques, extension and projection, are used to offer an enhanced understanding 
of Japanese strategic conduct from a cultural perspective. In addition, it is proposed that this latent orientation toward the principles of aikido may be the contextual foundation of Japanese marketing protection. The present study first considers aikido's contribution to Japanese marketing strategy. Next, a general discussion of aikido covers the combat philosophy concentrating on differences between the U.S. and Japan's competitive orientation. Finally, an examination of the aikido defense tactics of extension and projection focuses on its use in marketing strategy with managerial implications offered.

\section{Aikido's Relevance to Combat and Marketing Competition}

Marketing strategy is convincingly compared to military science for use in developing viable business strategies for market competition. Kotler and Singh (1981) drew parallels between marketing and military science offering a view of business as a battlefield. Ries and Trout (1986) used Kotler and Singh's work as a base in generating and implementing business strategies. Cook (1983) offered an arrangement to aid executives in choosing the optimal strategy while Parasuraman and Varadarajan (1985) propounded new dimensions for progress in a critical analysis of Cook's framework.

While the marketing/military science fusion offered fresh perspectives on market competition, aikido's hand-to-hand combat offers further insight into another facet of Japanese managers' orientation. While embracing some common elements, the Japanese personal combat technique of aikido differs both in philosophy and action when compared to the traditional Western combat sport of boxing. Knowledge of these differences in a cultural orientation toward conflict may offer Western firms the enhanced understanding required to successfully compete with the Japanese. Table 1 provides a summary of the different orientations between aikido and boxing.

Table 1: A Comparison of Japanese and Western Martial Arts

AIKIDO

To avoid or stop the attack

Circular

Horizontal, vertical

A long-term

vision

RELATIONSH
WITH TIME

PERSPECTIVE

TOWARDS OPPONENT
BOXING

To destroy the opposition

Linear

Frontal

Immediate results

Cooperative Combative

BALANCE

Retain always

Willingness to temporarily sacrifice in an attack 


\section{Aikido's Philosophy}

The word "aikido" means "method or way (do) for the Coordination or Harmony (ai) of Mental Energy or Spirit (ki)” (Westbrook and Ratti 1970). Westbrook and Ratti (1970) suggest aikido's philosophy is best understood by examining its: (1) objectives, (2) theory, and (3) principles.

\section{Aikido Objectives}

Westbrook and Ratti (1970) relate three crucial elements that differentiate aikido from other Japanese martial arts. First, aikido as self-defense is entirely reactive. There is no attack strategy. Second, an aikidoist's source of power is derived from the person's center or "hara" where a concentration of inner energy known as "ki" exists. This energy is integrated in aikido techniques to dramatically bolster the physical mechanics. Third, aikido's evasive movement strategy heavily relies on circularity or "sphericity."

Another contrasting element of aikido compared to some Japanese combat styles includes responsibility for the attacker's welfare. When using aikido properly, physical aggression is neutralized swiftly with control over the attack so effective that self-defense is possible without inflicting serious injury upon an aggressor. This Japanese culturallybased attitude towards competitors has proved to be advantageous against highly visible and vocal U.S. firms in the automobile or computer industry. For example, if Japanese firms were to attempt to use a more dramatic "knock-out" punch on a company such as Chrysler it could generate considerable hostility, ultimately leading to a loss of goodwill, market access, and sales potential.

Aikido also offers a method to strengthen the mind and body while fusing the person's physical and mental powers to emerge as a more fully integrated individual. Japan certainly emulates this style with Kotabe's (1984) “Japan, Inc." merging of business, labor, government and the general public interest to strive toward superiority in the global marketplace.

\section{Aikido Defense Theory}

Aikido defense consists of perception, evaluation-decision, and reaction (Westbrook and Ratti 1970). Aikidoists strive to develop an ever-vigilant awareness of events to avoid physical attack in the same way marketers seek to use Levitt's (1975) suggestion pertaining to myopic corporate vision to eschew unexpected marketing attacks. Once the awareness of an attack is established, the most appropriate defense is applied based on a split-second analysis. The effectiveness of any defensive plan depends largely upon the time lapse between the first consideration an attack might occur and the defensive reaction.

\section{Aikido Principles}

A primary aikido defense factor includes dynamic momentum of convergence or the amount of force generated by the attacker (Westbrook and Ratti 1970). The aikidoist is acutely aware that a human body in motion becomes extremely easy to maneuver and its vertical stability is greatly reduced. Aikidoists seek to induce the attacker to move 
faster and more recklessly thereby leading to a greater loss of balance and control. To illustrate this tactic in a business context, consider Japanese auto firms' relentless focus on shortening product development cycles. This allows them to exact a premium for the exclusive product, react more rapidly to changing market demands, generate increasingly modern technology and focus enormous pressure on U.S. competitors. An early U.S. automobile makers' response to this Japanese strategy can be illustrated by General Motor's premature introduction of the Pontiac Fiero. While the Fiero was introduced to the market ahead of other low-cost, two-seat sport cars, it had a tendency to burst into flames (Bussey and Sease 1988).

\section{The Principle of Extension}

An intrinsic element of aikido is represented by ki or a person's centralized energy. This aspect animates the application of all aikido techniques when practiced properly. All persons possess ki. However, only when the force is concentrated in a single, unified stream is energy extended and channeled into a nearly irresistible action of defense through physical movements.

While the vast majority of aikido uses involve a dynamic ki, there is also use of a static ki frequently described as the "unbendable arm" and is a demonstration of the extension principle (Westbrook and Ratti 1970). In short, an aikidoist is able to channel concentrated ki through an arm and, although the muscles of the arm are not strained or muscular tension generated, another individual is not able to bend the arm. This physical demonstration points out the difference in the West and East perspectives. Westerners tend to measure strength in terms of muscle power, while those in the East often refer to the "power of the spirit" or "mind over matter." This refers to an integration of a person's mental and physical attributes.

If a person does not maintain this "unbendable arm" at all times (or the extension is abandoned), the person will be unable to perform the aikido defensive techniques correctly. This "unbendable arm," permits the defender to guide and direct an attacker's force without smashing directly into it (Westbrook and Ratti 1970).

As a business example of the pervasive nature of the protectionist philosophy of the extension principle, consider Japan's ability to protect itself from import products. Foreign pressure exerted on Japan has forced Japan to lower many of its formal trade barriers. Nevertheless, informal cultural barriers remain nearly impenetrable. At one point, approximately sixty percent of Japan's city governments required national retailers to gain approval from all existing shopkeepers within one-third mile radius of the proposed site before opening (Darlin 1988). Further, the Ministry of International Trade and Industry (MITI) typically required 8-10 years to pass before a retail establishment was allowed to open, and once open approximately seventy-one licenses were needed to operate the establishment (Darlin 1988). These factors allowed the Japanese "Papa-Mama stores" to gain fifty-six percent of retail sales (compared to 3\% in the U.S. and 5\% in Europe) and to control a majority of store shelves that could potentially display U.S. products (Darlin 1988).

A second example of this "extension" defense is illustrated with Dow Corporation's attempts to build a plant in Japan. Dow's efforts to build a plant were first blocked by 
MITI (Mason 1992). When Dow tried to purchase land in Japan for a plant, local Japanese civic authorities again blocked attempts. After considerable time and expense, Dow decided to change the proposed site location. Once again, a different Japanese locality thwarted Dow's attempt to purchase the necessary land for plant construction. Dow then tried to use the Japanese media to explain its position and the benefits the locals could expect to enjoy from the plant construction. Locals counter-attacked by calling Dow a foreign influence that would operate in an intrusive, non-Japanese manner. Dow never constructed the plant (Mason 1992).

An example of parrying through extension and then leading an opponent into a relatively harmless circuit around the defender's center is found in Japanese dealings with Motorola. The Ministry of Posts and Telecommunications in Japan excluded the U.S. firm of Motorola from the majority of the Japanese car phone market by giving them a license for only western Japan, excluding Tokyo. The car phone market in Tokyo was awarded to Nippon Telegraph and Telephone and Teleway of Japan (The Wall Street Journal 1987). Therefore, the Motorola marketing strike was not directly blocked, but deflected to a relatively harmless area around the defender's center of power.

There are times when Japanese will abruptly shut out foreign-based multinational corporations. Japan's Nippon Telegraph \& Telephone Public Corp. grants contracts exclusively to a few local suppliers, resulting in no opportunities for outsiders to gain such business regardless of price, service, or quality (Business Week 1982).

Japanese martial arts may be generally divided into "soft" and "hard" dynamic ki systems. In aikido, the ki or centralized energy acts as more of an all-pervading, forcefield type, as compared with the concentrated and laser-like form of energy that cuts through an opposing target, penetrating anything in its line. "Hard" ki is more sharp and concentrated to a dangerous point like that found on a Japanese sword. Strikes are predominantly straight (direct), although there are circular forms of hard ki (slashing extension). This very concentrated form of ki usually requires that a single anatomical weapon, i.e., arm, leg, hand, foot, elbow, etc. be employed to deliver the force of the focused energy.

The "soft" ki appears as an evenly diffused and expanding power that acts like a huge sphere to completely envelop the target or spin tangentially against it (Westbrook and Ratti 1970). Its force brings to mind power more resembling that of "massed wind or water." "Soft" ki does not cut through the target; it sweeps it away in a tangential, circular pattern sending the target spinning in centrifugal unbalance or extends and stretches it in a desired direction. This ability to impart additional momentum to an attacking force and send him or her in a harmless direction is considered in a discussion of projections.

\section{Projections}

Projections are techniques of neutralization in which physical contact between the defender and aggressor ceases (although the defender's follow-through continues) when the attacker is thrown spinning to the ground. Projections are possible since the attacker is extended dynamically in the desired direction and the defender's position and central spinning motion is faster than the attacker's peripheral motion as he or she circles the 
defender (Westbrook and Ratti 1970). The attacker's head, often in direct contact with the defender's body (the spinning axis of the action), is extended ahead of the rest of his or her body which follows in a circular pattern.

In a projection, usually the aggressor's orbital motion and frontal extension is ultimately channeled back in the direction of the source (Westbrook and Ratti 1970). In short, the attacker's momentum is led in a circular pattern. This dynamic reversal or circle must be achieved smoothly, with minimal interruption. The unified projection is derived from simultaneous centralization and extension of centralized energy. This seeming paradox is often referred to as "explosive stability."

\section{Leg Sweep}

In a projection known as the aiki otoshi, the defender's hips are used to remove the attacker's feet from the ground and project him or her back down to the ground (Westbrook and Ratti 1970). The aikidoist sweeps both legs of the aggressor from the front, practically clasping them together. The defender's lower abdomen at this point is the operational center of the projection. The defender releases the attacker when her or his feet are high in the air and trunk is parallel to the ground. An important point in this technique is never to allow the central weight of the attacker to fall on the defender. The attacker's total weight, at the moment when natural supports are swept away, is left floating in space, not resting on the defender. Therefore, the action is swift and effortless, since the aikidoist is not "loading the attacker up" onto his or her hips, which is incorrect, but simply "cutting the aggressor down" from underneath. The attacker's legs, once the central weight no longer presses down, become extremely light and easy to maneuver. Correct timing of the attacker's unbalance and the defender's circular sweep determines the projection's success.

This technique has been used effectively in the computer field where Japanese companies have adopted strategies differing from those usually chosen by U.S. computer prodicers. Hitachi Ltd. entered the U.S. as an original equipment manufacturer (OEM) to Intel Corporation that sold Hitachi computers under Intel's name. As Intel grew more dependent on Hitachi to supply computers, Hitachi had a greater opportunity to study and understand the distribution intricacies of the U.S. computer industry. Hence, while Intel gained sales momentum partially inspired by the Japanese firm, Intel's market position became more dependent on the Japanese support (The Japan Economic Joumal 1980).

Based on aikido principles, one option for Hitachi is to continue to inspire more and more Intel dependence on Hitachi and then sweep the means of support out from under Intel. This could be accomplished by recruiting Intel's distribution people, with business contacts and practices as the primary goals. Another possibility is for Hitachi to generate more joint projects with U.S. firms for purposes of distribution. This may pressure Intel to offer concessions in the form of distribution control instead of profits. This arrangement does not permit the international firm an opportunity to generate a strong identity in the local market. However, the joint venture does allow Hitachi to reach a high volume more quickly by sacrificing independence and control over its distribution system. Japanese firms often have OEMs with a number of different firms at once. 


\section{Corner Drop}

Another aikido projection technique is known as sumi otoshi (corner drop) (Westbrook and Ratti 1970). This throw permits the defender to channel the attacker's force on one side of his or her body, that side becoming the axis around which the aggressor rotates in unbalance until falling. This motion involves a particularly delicate, spiraling pattem which is a key factor in drawing the attacker in a direction away from the vulnerable area of the defender.

An example of this technique is demonstrated by the competition in super-computers between Japanese and U.S. firms. The U.S. dominated super-computer industry pressured Japan's government to purchase the superior ptoduct for appropriate use (Ratan 1991). The purchase was blocked by the Japanese government on one pretext after another for a period of seven years, resulting in the U.S. firms' resources being directed toward bureaucratic battles and away from technical innovation in the super-computer business. By the time the U.S. computer firms were able to break down the barriers thrown up by the Japanese government to permit selling to the Japanese public-sector buyers, the Japanese computer firms had learned how to make the machines themselves and had secured a majority of Japan's government market (Ratan 1991).

\section{Scarf Throw}

Another intriguing aikido projection technique is the "scarf" throw. The characteristic feature of this method is wrapping one of the attacker's arms around his or her own neck to cause the attacker to rotate vertically around the person's own spinal axis (Westbrook and Ratti 1970). This aikido move is illustrated in the global marketplace through sales of computer components. Japan has managed to engender competition within the U.S. computer industry to the advantage of Japan. Japanese technology has become so important to IBM, Apple, Compaq, and Tandy that they defended Japan's electronics exporters against charges by smaller U.S. competitors claiming Japan is dumping flat-panel displays (Ratan 1991). The U.S. computer giants say American suppliers cannot meet the demand for this crucial computer component. In essence, one appendage of the U.S. industry is used to "choke" and "project" another part of the U.S. industry (Ratan 1991).

\section{Dangling Bait}

While many of the aikido projection techniques are structured to take advantage of an attacker gripping the defender, some are performed dynamically so the attacker does not have a chance to securely clutch a wrist (Westbrook and Ratti 1970). It is extremely important for the defender not to move too fast or the attacker will lose the defender causing the defender to lose the aggressor. It is equally crucial not to move too slow or the attacker will be able to seize and control the defender's wrist. This is a peculiar, tantalizing form of motion which makes a target appear to be so near and accessible. In reality, the target is receding and drawing the aggressor out into uncontrolled extension before the attacker realizes what has happened.

If the aggressor has already contacted the defender's wrist, it is still possible to lead the attacker out into unbalanced extension because "contact" does not mean "hold." A 
hold requires a few moments to become stabilized (Westbrook and Ratti 1970). A hold, to be secured, requires some form of stability or balance. Providing the defender flows smoothly with the motion of the attacker's hands toward the defender's wrists, the attacker does not retain a strong balance because the defender is fading away, and the aggressor is stretching forward. The aggressor's power still flows out toward a target he or she cannot grasp and cannot stop.

This strategy of dangling the possibility of a solid hold on the Japanese market for U.S. businesses is a technique the Japanese businesses have used with regularity. According to Killing (1982), in Japan foreign multinational companies typically used joint ventures to gain access to distribution channels, while the Japanese partners were primarily interested in new technology. The difference between the two objectives is dramatic. While access for U.S. firms to the Japanese market is valuable, that access can be blocked abruptly, offering no future value. However, Japanese access to U.S. technology results in efficiencies in research and development, and ultimately leading to industry control by the Japanese firm.

When assessing this type of exchange in the history of joint ventures between Japanese and non-Japanese firms, a pattem appears to emerge. According to Killing (1982), between 1972 and 1976 some 90 major joint ventures eventually failed in Japan. Many of these ventures involved large U.S. technology oriented firms such as General Mills, TRW, and Avis. The U.S. firms gained access to the Japanese markets for a brief period and the Japanese firms retained use of the technological knowledge forever.

\section{Somersault}

Another interesting projection technique appears simple, but is one of the most sophisticated examples of centralization coordinated with an opponent's movement of attack. Combat is suddenly shifted from a vertical dimension to the horizontal before the attacker realizes what is happening and can adapt the attack to the new circumstances. Hence, the projection rests upon an accurate estimation of the opponent's commitment to the primary attack-an essential aspect for successful use of the technique.

The aikido artist leads the attacker out with a few circular steps in order to increase the momentum of the initial attack motion. As the attacker converges, the defender sinks down deeply under the aggressor as if the defender was a huge stone suddenly emerging in the opponent's way. The defender then rises behind the attacker after the person has soared up and over the aikidoist's body in the somersault necessitated by the abruptness of the aikido maneuver and by the attacker's own dynamic commitment to the attack (Westbrook and Ratti 1970).

An example of this technique may be seen in the U.S. attack on the Japanese tobacco market. R.J. Reynolds saw what appeared to be an excellent opportunity to market its modern long, brown-wrapper cigarette More in Japan (Jeannet and Hennessey 1988). The new style hit the market and seemed ready to take a significant share of the market. Abruptly, the Japanese Tobacco and Salt Public Corporation, a government monopoly, swept the legs of R.J. Reynolds out from under them by keeping More in a limited test market for two years. During those two years, the Japanese developed their own brown- 
wrapper cigarette. By the time More was released to the general market, it faced a direct domestic competitor already securely entrenched in the niche (Jeannet and Hennessey 1988).

A second example of such a technique is found in the steel-making industry. For years, the U.S. was a dominant global industrial power and operated in a fashion which assumed such a world position would remain. Management in the steel-producing organizations, assuming long-term industry dominance, offered long-term commitments to labor unions which made layoffs costly. At the time, the possibility of forced layoffs seemed extremely remote, if not impossible, and appeared to be a costless bargaining chip for management. Then Japan greatly expanded its steel-making capacity in the $1970 \mathrm{~s}$ while U.S. firms tried to keep pace. Presently, with a global over-capacity for producing steel U.S. plants are unprofitable (The Wall Street Journal 1987).

Japan spurred the over-development or incited the momentum of the U.S. steel-making capacity based on the worldwide market. Now with the scale of operations of U.S. steel mills, the U.S. firms cannot shut down unprofitable plants because of the high cost of laying off workers. Japan, on the other hand, has cut production capacity and is able to patiently wait for the U.S. firms to self-destruct or severely weaken themselves before rising again to capture an increasing market share (The Wall Street Journal 1987).

\section{Managerial Implications}

The managerial implications of this cultural interpretation of Japanese corporate strategy are threefold: (1) Japanese and Western firms while engaging in the same game are playing by implementing different principles, (2) Japanese firms have a very different orientation toward competition, (3) to be successful in engaging in competition with the Japanese, Western corporations must attempt to understand the both the strategy and the cultural underpinnings that underlie much of Japanese corporate behavior.

One recent attempt to understand the latent dimensions of Japanese corporate strategy was Kotabe and Duhan's (1993) analysis of 882 Japanese manufacturing corporations. Kotabe and Duhan (1993) found that Japanese firms tend to fall into one of three distinct strategy clusters. These strategic clusters are based on the interaction of market position and product related factors with the stage of the product life-cycle and business orientation. High performing Japanese manufacturers based on relative measures of ROI tended to be categorized into one of three strategic clusters: (1) "brand skeptics," (2) "true believers," or (3) "mavericks" (Kotabe and Duhan 1993).

Firms that adopt a brand skeptic strategic cluster create their competitive advantages through product innovation. True believers utilize both brand development and value enhancement in an effort to develop a sustainable competitive advantage (Kotabe and Duhan 1993). Firms following the maverick strategic cluster tend to highly cost focused, with constant efforts made to achieve a cost oriented advantage. The implications of the present study and the findings of the Kotabe and Duhan (1993) analysis suggests that Western firms must be prepared to compete with firms that tend to: (1) be innovative, (2) constantly seek to enhance value to the customer, (3) develop unique and sustainable 
cost advantages, (4) have a long-run perspective, (5) prefer cooperation rather than competition, and (6) typically have an overall objective of long-run survival and ultimately market dominance.

\section{Strategic Responses}

While specific aikido techniques were cited previously with corresponding examples, what is more salient to the Western manager is to develop an appreciation of the principles underlying Japanese strategy and appropriate strategic responses. Five strategic responses are offered to Western strategists who operate from a culturally derived linear "boxing" perspective and attempt to compete with the swirling and obtuse aikido-oriented Japanese.

First, Western strategists should not interpret soft resistance from Japanese firms as a forecast of a market concession and impending Western success. An aversion to a boxing style of "toe-to-toe" marketplace combat by the Japanese does not imply surrender. In this situation, the Western manager must respond by carefully assessing if the firm is being guided by the aikidoists down an inopportune path. The strategic advantage accruing to the Japanese for utilizing this obtuse strategy is that the opponent may fail to comprehend the incorrect decision and direction until it is too late to effectively compete.

Second, Western strategists should carefully consider all of the consequences when attempting to beat the Japanese "at their own game," particularly in situations when the Japanese appear to have only a marginal competitive advantage. The fatal attraction of a relatively easy target for an aggressive boxing-oriented Westem firm may encourage it to attack with reckless abandon. The false appearance of being nearly in reach may be the "bait" utilized to draw Western firms into the ineffective response of attempting to catch-up, by re-allocating time, capital, and critical resources from other more advantageous projects. The Japanese firm may then continue advancing just slightly ahead of the Western firm retaining market share while squandering the competition's resource base.

Third, the Japanese ability to recognize and react to market demand dynamics in a more timely fashion than Western firms typically respond may be due to the more intuitive nature of the aikido-oriented strategists. Japanese decision makers tend to be more likely to trust feelings and subtle signals than an analytical Westerner. This acute sense of nearly imperceptible movement provides the aikido master with the additional time required to prepare an appropriate response to an attack. While Western boxers typically burn energy bobbing and feinting non-stop as a defensive technique, the aikidoists remain motionless until movement by the opponent. What appears as a lightning Japanese response to environmental dynamics is owed to a sensitive intelligence system and superior timing. Westerners should try to emulate the Japanese in this respect by sharpening their market perceptiveness with enhanced marketing information and decision support systems.

Fourth, Westerners should respond to the circular orientation of the Japanese competitors by seeking a harmonious balance in their strategic plans, core capacities, production operations, and market implementations by refraining from a heavy dependence on any particular customers, suppliers, and distributors. Leaning too heavily on one support of- 
fers the Japanese competitor a much greater opportunity to sweep away that critical prop, leaving the Western firm unbalanced and vulnerable.

Fifth, like aikido masters, Japanese firms are highly cognizant of stability and seek exceptional balance with extensive and long-range planning. For example, Japanese keiretsus bolster stability by engineering a high level of interdependence between the manufactures, suppliers, creditors, and customers. This institutional interdependence results in a system of captive exchange partners that engage in Dwyer, Schurr, and Oh's (1987) system of relational transactions, exhibiting unswerving loyalty regardless of market, technology, or price changes. Dwyer, Schurr, and Oh's (1987) concept of discrete transactions describes the principle governing exchanges between Western firms that values short-term performance over inter-organizational loyalty. Like boxers launching a strike, Western firms will temporarily sacrifice stability when making abrupt changes in suppliers or customers. Once the punch is landed, the boxer rapidly seeks equilibrium again just as the Western firm attempts to re-establish balance after market changes. Westerners may attempt to exploit the institutional interdependence of the keiretsus with its implicit long term supplier relationships by constantly altering the industry's distribution technology and channel structure.

\section{Summary}

Analogies drawn between military science and marketing strategies have helped marketers attain better understanding of strategies possible in competition. This manuscript extends this tradition by examining the Japanese martial art of aikido. Since some aikido principles differ greatly from those of American combat and sport strategies, this paper offers insight into an unexplored aspect of Japanese marketing philosophy that may prove useful in the decision- making process of Western managers.

Specific aikido defense principles of extension and projection were examined in detail. By examining these principles, it was demonstrated how extension and projection are used by Japanese businesses to protect themselves from attacks by foreign business forces. By understanding the cultural context of how the Japanese aikidoist reacts to any type of threat from an outside force, the U.S. strategist can better plan ventures involving competition with Japanese firms. In addition, Western managers may also benefit by understanding the latent strategies successful Japanese corporations have adopted such as customer value enhancement, innovation, cost leadership, relational exchange, and differentiation as potential strategic responses.

\section{References}

Business Week. 1982. "High-Technology Gateway," (August 9): 40.

Bussey, John and Douglas R. Sease. 1988. "Speeding Up." In Applications in Basic Marketing 1990, 94-95. Eds. E. Jerome McCarthy and William D. Perreaut. Homewood, IL: Richard D. Irwin, Inc. 
Cook, Victor J. Jr. 1983. "Marketing Strategy and Differential Advantage."Journal of Marketing, 47 (Spring): 68-75.

Darlin, Damon. 1988. "Papa-Mama Stores in Japan Wield Power to Hold Back Imports." In Applications in Basic Marketing 1991-1992, 182-183. Edited by E. Jerome McCarthy and William D. Perreault. Homewood, IL: Richard D. Irwin, Inc.

Dwyer, F. Robert, Paul H. Schurr, and Sejo Oh. 1987. "Developing Buyer-Seller Relationships." Journal of Marketing 51(2): 11-27.

Ishihara, Shintaro. 1989. The Japan That Can Say No. New York: Simon and Schuster, 21-68.

Jeannet, Jean-Pierre and Hubert D. Hennessey. 1988. International Marketing Management. Boston: Houghton Mifflin Company, 173-174.

Johnson, Chalmers. 1985. "The Institutional Foundations of Japanese Industrial Policy." California Management Review, 27(4).

Killing, J. Peter. 1982. "How to Make a Global Joint Venture Work." Harvard Business Review (May-June): 121.

Kotabe, Masaaki. 1984. "Changing Roles of the Sogo Shoshas, the Manufacturing Firms, and the MITI in the Context of the Japanese 'Trade or Die' Mentality." Columbia Journal of World Business 14(3), 33-42.

Kotabe, Masaaki and Dale F. Duhan. 1993. "Strategy Clusters in Japanese Markets: Firm Performance Implications." Journal of the Academy of Marketing Sciences 21(1): 21-31.

Kotler, Philip and Ravi Singh. 1981. "Marketing Warfare in the 1980s." Journal of Business Strategy 1(Winter): 30-42.

Levitt, Theodore. 1975. "Marketing Myopia." Harvard Business Review 53(September-October): 26-44.

Mason, Mark. 1992. "Foreign Direct Investment in Japan: Lessons from Business History." The International Executive 34 (January/February); 7-13.

Parasuraman, A. and P. Varadarajan. 1985. "More on Marketing Strategy and Differential Advantage." Journal of Marketing 49(Spring): 124-128.

Ratan, Suneel. 1991. "The Big Split." Fortune (May 6) 123(9): 38-42.

Ries, Al and Jack Trout. 1986. Marketing Warfare. New York: McGraw-Hill.

The Japan Economic Journal. 1980. "Hitachi and Fujitsu Step Up Their Computer Exports." (May 6): 9. 
Spring 1994 Cotter, et al.: Strategy as a Culturally Dependent Phenomenon

The Wall Street Journal. 1987. "Glutted Markets." In Applications in Basic Marketing 1990 Edition, 6-10. Eds. E. Jerome McCarthy and William D. Perreault. Homewood, IL: Richard D. Irwin, Inc.

Westbrook, A. and O. Ratti. 1970. Aikido and the Dynamic Sphere. Rutland, VT: Charles E. Tuttle Company. 